\title{
Dirichlet-Neumann problem for the partial differential equations with deviation over the space argument
}

\author{
Pukach P.Ya. ${ }^{1}$, Repetylo S.M. ${ }^{1,2}$, Symotiuk M.M. ${ }^{1,2}$, Vovk M.I. ${ }^{1, 凶}$
}

Dirichlet-Neumann problem for the typeless high order partial differential equation with deviating over the space argument is studied in the domain, which is the Cartesian product of the segment $(0, T)$ and the unit circle $\Omega=\mathbb{R} /(2 \pi \mathbb{Z})$. Dirichlet-Neumann problem for hyperbolic equations and their systems in case with absent argument deviation $h$ has been studied by the authors before. Correct solvability conditions have been established for these problems for almost all (with respect to Lebesgue measure) numbers $T>0$ and for almost all (with respect to Lebesgue measure) vectors, constructed by coefficients of the equation.

In this paper, the solvability conditions of the problem for $h \neq 0$ are described and the influence of the deviation $h$ on the solvability of the problem is studied. The solution of the problem is constructed in the form of the series with respect to the systems of orthogonal functions. Metric estimations (of exponential type) are proved for small denominators appearing during construction of the problem solution. These estimations guarantee the correctness of the problem in Sobolev spaces for almost all (with respect to Lebesgue measure) values $T>0$ and for almost all (with respect to Lebesgue measure) values $h \in[0,2 \pi)$. The obtained results are based on the fact that the corresponding characteristic determinant permits factorization in the form of the product of hyperbolic functions with integer parameters.

Key words and phrases: Dirichlet-Neumann problem, partial differential equation, deviation over the space argument, small denominators, metric approach.

\footnotetext{
${ }^{1}$ Lviv Polytechnic National University, 12 Bandera str., 79013, Lviv, Ukraine

2 Pidstryhach Institute for Applied Problems of Mechanics and Mathematics, 3b Naukova str., 79060, Lviv, Ukraine

$\triangle$ Corresponding author

E-mail: ppukach@lpnu.ua (Pukach P.Ya.), repetylosofiya@gmail.com (Repetylo S.M.), quaternion@ukr.net (Symotiuk M.M.), mira.i.kopych@gmail.com (Vovk M.I.)
}

\section{Problem statement. Introduction}

Let us consider the Dirichlet-Neumann problem for the partial differential equation with deviating argument

$$
\begin{gathered}
\frac{\partial^{2 n} u(t, x)}{\partial t^{2 n}}+\sum_{j=1}^{n} a_{j} \frac{\partial^{2 n} u(t, x+2 j h)}{\partial t^{2 n-2 j} \partial x^{2 j}}=0, \quad(t, x) \in(0, T) \times \Omega, \\
\left.\frac{\partial^{2 j-2} u(t, x)}{\partial t^{2 j-2}}\right|_{t=0}=\varphi_{j}(x),\left.\quad \frac{\partial^{2 j-1} u(t, x)}{\partial t^{2 j-1}}\right|_{t=T}=\varphi_{n+j}(x), \quad j=1, \ldots, n,
\end{gathered}
$$

where $\Omega=\mathbb{R} /(2 \pi \mathbb{Z})$ is a unit circle, $h \in \Omega, a_{j}, j=1, \ldots, n$, are the complex numbers. The partial differential equation (1) connects the values of the unknown function $u(t, x)$ and its derivatives with respect to different space argument values. 
The partial differential equations with deviating arguments describe the systems taking into account the fact that interaction between the system parts is realized not instantly but with some delay on time or spatial variables. A lot of literature is devoted to the various aspects of the differential equations with a deviating argument theory and its applications (see, for example, $[1-3,6-8,15]$ and bibliography therein).

Dirichlet-Neumann problem (2) for hyperbolic equations and their systems (1) in the case $h=0$ was studied in papers $[13,14]$. There were established the conditions of correct solvability for the considered problems in Sobolev spaces if the argument deviation is absent $(h=0)$ in equation (1). Fourier series convergence for solution of the problem is connected with the problem of small denominators [11,12]. The metric approach is applied in above cited articles for overcoming the negative influence of the small denominators. It was established for almost all (with respect to Lebesgue measure in $\mathbb{R}$ ) numbers $T>0$ and for almost all (with respect to Lebesgue measure in $\mathbb{R}^{n}$ ) vectors $\vec{a}=\left(a_{1}, \ldots, a_{n}\right)$, constructed by coefficients of the equation (1).

The article [10] sets the stability conditions for the solution of Cauchy problem for the firstorder and second-order equations by a time variable with deviations of spatial coordinates. These conditions are expressed via the properties of the deviations over the spatial arguments values. The action of the operator $T_{h}$ on the deviation over the spatial argument $T_{h} u(t, x)=$ $u(t, x+h)$ can be interpreted as the action of the pseudo-differential infinite order operator $u(t, x+h)=\exp (i h \partial u(t, x) / \partial x)$. Thereby, the results of this paper are closely related to the research conducted in the article [9], which deals with the boundary problems for equations with pseudo-differential operators in infinite domains by spatial coordinates and the nonlocal problems for the differential-operator equations $[4,5]$.

\section{Main notation}

Let us denote mes $A$ as Lebesgue measure in $\mathbb{R}$ of a measurable set $A \subset \mathbb{R} ; H_{\alpha}(\alpha \in \mathbb{R})$ as the space being obtained as completion of the trigonometric polynomials space $\varphi(x)=$ $\sum \varphi_{k} e^{i k x}$ with the finite degree in the norm

$$
\left\|\varphi(x) ; H_{\alpha}\right\|=\left(\sum_{|k| \geq 0}\left|\varphi_{k}\right|^{2} w_{k}^{2}(\alpha)\right)^{1 / 2}, \quad w_{k}(\alpha)=(1+|k|)^{\alpha}, \quad k \in \mathbb{Z} ;
$$

$C^{n}\left([0, T] ; H_{\alpha}\right)$ is space of the functions $u(t, x)=\sum_{|k| \geq 0} u_{k}(t) e^{i k x}, u_{k} \in C^{n}[0, T], k \in \mathbb{Z}$. Their derivatives $\partial^{j} u / \partial t^{j} \equiv \sum_{|k| \geq 0} u_{k}^{(j)}(t) e^{i k x}, 0 \leq j \leq n$, belong to the space $H_{\alpha}$ at fixed $t \in[0, T]$ and are continuous by $t$ on $[0, T]$ as the space elements. Norm in $C^{n}\left([0, T] ; H_{\alpha}\right)$ is prescribed as

$$
\left\|u(t, x) ; C^{n}\left([0, T] ; H_{\alpha}\right)\right\|=\sum_{j=0}^{n} \max _{t \in[0, T]}\left\|\partial^{j} u(t, x) / \partial t^{j} ; H_{\alpha}\right\| .
$$

\section{Solution uniqueness}

We suppose that $a_{n} \neq 0$ and that the roots $\sigma_{1}, \ldots, \sigma_{n}$ of polynomial $\sigma^{n}-a_{1} \sigma^{n-1}+\ldots+$ $(-1)^{n} a_{n}$ are different and simple. Let us find the solution of the problem (1), (2) represented as series $u(t, x)=\sum_{|k| \geq 0} u_{k}(t) e^{i k x}$. Every function $u_{k}(t), k \in \mathbb{Z}$, is a solution of the next two- 
point problem for the ordinary differential equation:

$$
\begin{gathered}
u_{k}^{(2 n)}(t)+\sum_{j=1}^{n} a_{j}(i k)^{2 j} e^{i 2 j h k} u_{k}^{(2 n-2 j)}(t)=0, \\
u_{k}^{(2 j-2)}(0)=\varphi_{j, k}, \quad u_{k}^{(2 j-1)}(T)=\varphi_{n+j, k}, \quad j=1, \ldots, n,
\end{gathered}
$$

where $\varphi_{j, k}, k \in \mathbb{Z}$, are the corresponding Fourier coefficients of the functions $\varphi_{j}(x), j=$ $1, \ldots, 2 n$.

Equation (3) is expressed in case $k=0$ as $d^{2 n} u_{0}(t) / d t^{2 n}=0$, and the functions system $\left\{u_{0, q}(t)=t^{q-1}, q=1, \ldots, 2 n\right\}$ is its fundamental solutions one. Therefore the solution of the problem (3), (4) for $k=0$ is the next

$$
u_{0}(t)=\sum_{q=1}^{2 n} C_{0, q} q^{q-1}
$$

Constants $C_{0, q}, q=1, \ldots, 2 n$, in formula (5) are the solutions of the linear equations system

$$
\begin{cases}C_{0,2 j-1}(2 j-2) !=\varphi_{j, 0} & j=1, \ldots, n, \\ \sum_{q=2 j}^{2 n} C_{0, q}(q-1) ! T^{q-2 j} /(q-2 j) !=\varphi_{n+j, 0}, & j=1, \ldots, n .\end{cases}
$$

The system determinant (6), denoted as $\Delta(0)$, is written as

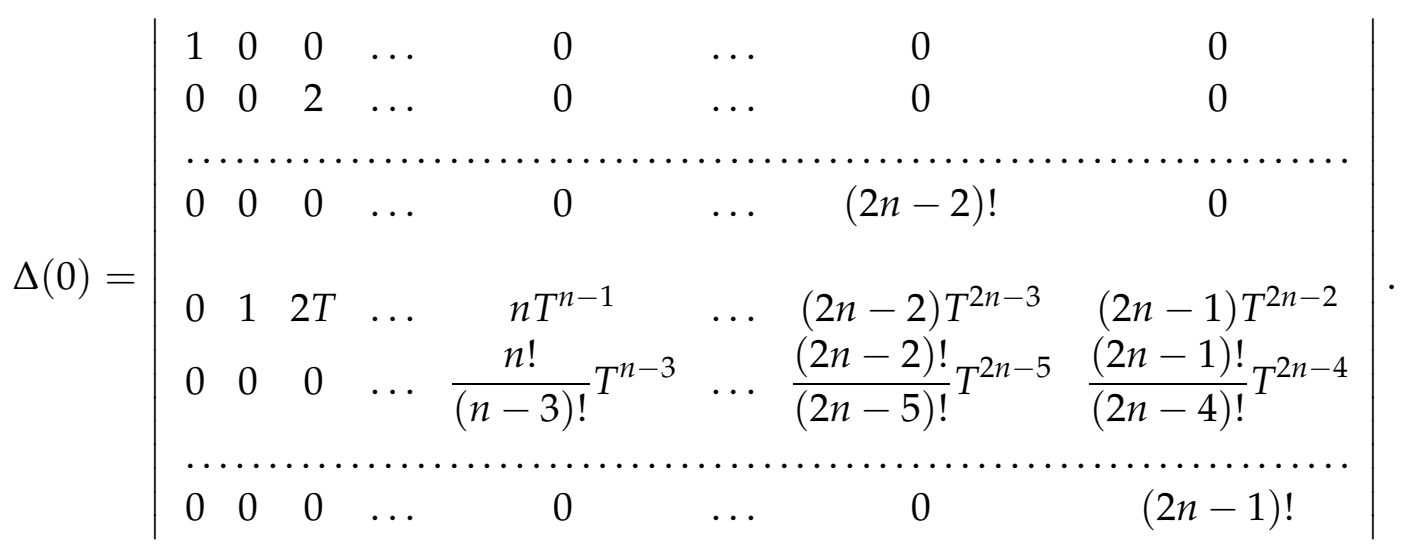

It is evident that

$$
\Delta(0)=-1 ! 2 ! \ldots(2 n-1) !
$$

Since $\Delta(0) \neq 0$, then the coefficients $C_{0, q}, q=1, \ldots, 2 n$, in the formula (5) can be uniquely determined from the system (6) via Cramer's rule. Consequently

$$
u_{0}(t)=\sum_{\ell, s=1}^{2 n}(-1)^{\ell+s} \varphi_{\ell 0} \frac{\Delta_{\ell s}(0)}{\Delta(0)} t^{s-1},
$$

where $\Delta_{\ell s}(0)$ is the cofactor of the element being the intersection of $\ell$ th raw and sth column in determinant $\Delta(0)$.

The next formula describes the fundamental solutions system of the equation (3) in case $k \neq 0$ :

$$
\left\{u_{k j}(t)=\exp \left(k \lambda_{j} e^{i k h} t\right), u_{k, n+j}(t)=\exp \left(-k \lambda_{j} e^{i k h} t\right), j=1, \ldots, n\right\},
$$

where $\lambda_{j}=\sqrt{\sigma_{j}}, j=1, \ldots, n$, and branch of the root is chosen with the condition $\sqrt{1}=1$.

Solution of the problem (3), (4) for $k \neq 0$ is represented as follows

$$
u_{k}(t)=\sum_{j=1}^{n}\left\{C_{k, j} \exp \left(k \lambda_{j} e^{i k h} t\right)+C_{k, n+j} \exp \left(-k \lambda_{j} e^{i k h} t\right)\right\}
$$


where the coefficients $C_{k, j}, j=1, \ldots, 2 n$, are determined from the linear algebraic equations

$$
\begin{cases}\sum_{j=1}^{n}\left\{C_{k, j}+C_{k, n+j}\right\}\left(k \lambda_{j} e^{i k h}\right)^{2 r-2}=\varphi_{r, k \prime} & r=1, \ldots, n, \\ \sum_{j=1}^{n}\left\{C_{k, j} \exp \left(k \lambda_{j} e^{i k h} T\right)-C_{k, n+j} \exp \left(-k \lambda_{j} e^{i k h} T\right)\right\}\left(k \lambda_{j} e^{i k h}\right)^{2 r-1}=\varphi_{n+r, k}, & r=1, \ldots, n .\end{cases}
$$

Let us denote $\eta_{j}=k \lambda_{j} e^{i k h}, \eta_{n+j}(k)=-k \lambda_{j} e^{i k h}, j=1, \ldots, n$. Characteristic determinant of the problem (3), (4), in case $k \neq 0$ is the next

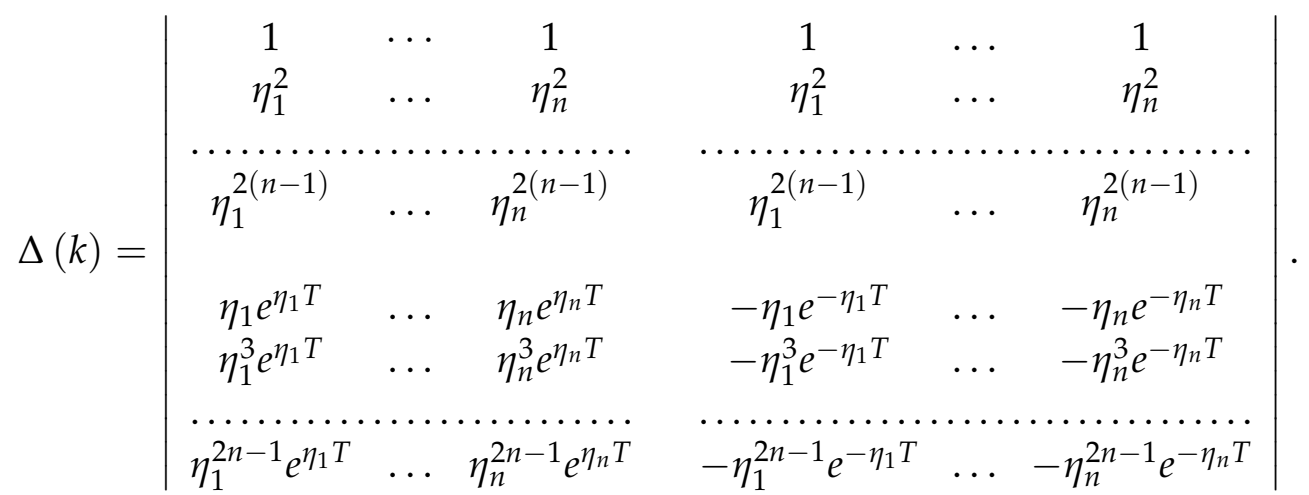

The next determinant is a result of the replacement of every $(n+j)$ th column with the difference the $(n+j)$ th and $j$ th, $j=1, \ldots, n$,

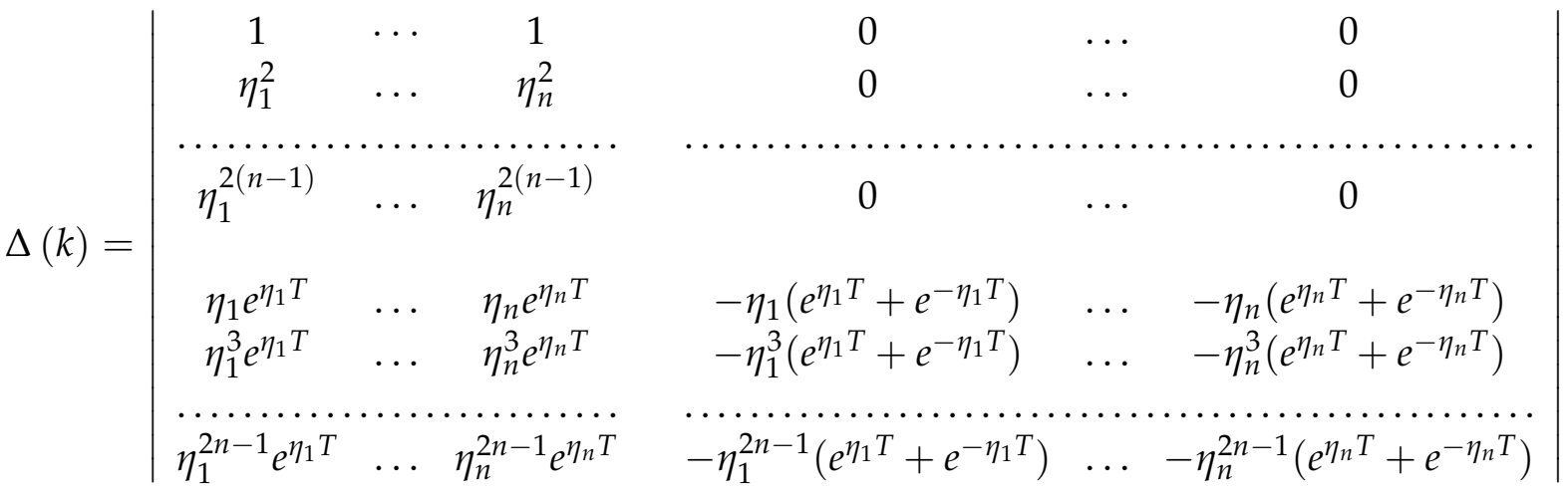

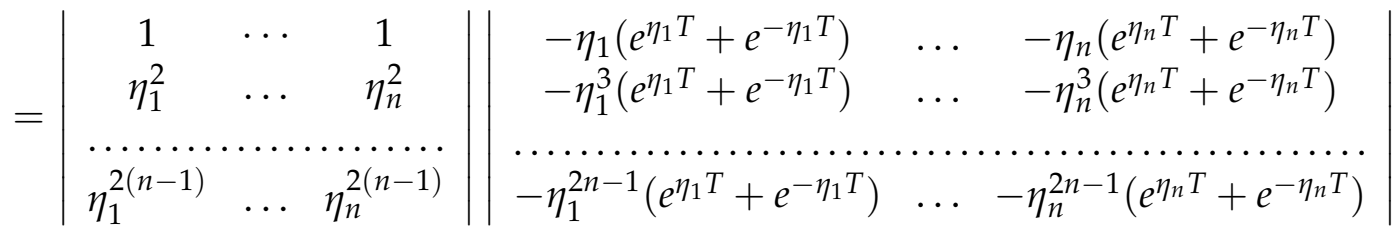

$$
\begin{aligned}
& =(-1)^{n} \prod_{1 \leq s<l \leq n}\left(\eta_{s}^{2}-\eta_{l}^{2}\right)^{2} \prod_{j=1}^{n}\left(\eta_{j}\left(e^{\eta_{j} T}+e^{-\eta_{j} T}\right)\right),
\end{aligned}
$$

therefore,

$$
\Delta(k)=(-1)^{n}\left(k e^{i k h}\right)^{2 n^{2}-n} \prod_{1 \leq s<l \leq n}\left(\lambda_{s}^{2}-\lambda_{l}^{2}\right)^{2} \prod_{j=1}^{n} \lambda_{j}\left(e^{k \lambda_{j} e^{i k h} T}+e^{-k \lambda_{j} e^{i k h} T}\right) .
$$

There are no two different solutions of the problem (3), (4) for every $k \in \mathbb{Z}$ if and only if $\Delta(k) \neq 0$. Basing on (7) and (10) the next theorem can be formulated.

Theorem 1. Solution of the problem (1), (2) is unique in the space $C^{2 n}\left([0, T] ; H_{\alpha}\right)$ if and only if the condition

is satisfied.

$$
\left(\bigcup_{j=1}^{n} \bigcup_{k \in \mathbb{Z}, k \neq 0}\left\{i \lambda_{j} k T e^{i k h}\right\}\right) \bigcap(\pi / 2+\pi \mathbb{Z})=\varnothing
$$


The proof of this theorem is analogical to [11, Theorem 2.1].

Remark 1. Condition (11) in the Theorem 1 can be rewritten as

$$
\prod_{j=1}^{n}\left(\cos ^{2}\left(\left|\lambda_{j}\right| k T\right)+\cos ^{2}\left(k h+\theta_{j}\right)\right) \neq 0, \quad k \neq 0,
$$

where $\theta_{j}=\arg \lambda_{j}, j=1, \ldots, n$.

Proof. Let us assume, that condition (11) is not true for some $k_{0} \in \mathbb{Z}$. Then at least for one $j, j=1, \ldots, n$, the next condition is satisfied

$$
\operatorname{ch}\left(k_{0} \lambda_{j} T e^{i k_{0} h}\right)=0
$$

Presenting $\lambda_{j}$ in terms of exponential form $\lambda_{j}=\left|\lambda_{j}\right| e^{i \theta_{j}}, j=1, \ldots, n$, condition (12) can be formulated as

$$
\operatorname{ch}\left(k_{0}\left|\lambda_{j}\right| T e^{i k_{0} h+i \theta_{j}}\right)=0
$$

Since zeroes of the function ch $z$ are numbers $z_{l}=i(\pi / 2+\pi l), l \in \mathbb{Z}$, then $k_{0}\left|\lambda_{j}\right| T e^{i k_{0} h+i \theta_{j}} \in M$, $M=\{-i(\pi / 2+\pi \mathbb{Z})\}$ arise from the formula (13).

Therefore there exists $p \in \mathbb{Z}$, such that

$$
k_{0}\left|\lambda_{j}\right| T e^{i k_{0} h+i \theta_{j}}=k_{0}\left|\lambda_{j}\right| T\left(\cos \left(k_{0} h+\theta_{j}\right)+i \sin \left(k_{0} h+\theta_{j}\right)\right)=-i(\pi / 2+\pi p),
$$

namely, the next equations system is true

$$
\left\{\begin{array}{l}
k_{0}\left|\lambda_{j}\right| T \cos \left(k_{0} h+\theta_{j}\right)=0 \\
k_{0}\left|\lambda_{j}\right| T \sin \left(k_{0} h+\theta_{j}\right)=-\pi / 2-\pi p
\end{array}\right.
$$

Since $\lambda_{j} \neq 0$ and $k_{0} \neq 0$, then the equations system (14) is equivalent to the system

$$
\left\{\begin{array}{l}
\cos \left(k_{0} h+\theta_{j}\right)=0 \\
\cos \left(k_{0}\left|\lambda_{j}\right| T\right)=0
\end{array}\right.
$$

that can be rewritten as equation $\cos ^{2}\left(k_{0} h+\theta_{j}\right)+\cos ^{2}\left(k_{0}\left|\lambda_{j}\right| T\right)=0$.

\section{Solution existence}

Let us suppose the condition (11) is satisfied. Coefficients $C_{k, j}, j=1, \ldots, 2 n$, are uniquely determined from the system (9) via Cramer's rule for every $k \neq 0$

$$
\left\{\begin{array}{l}
C_{k, j}=\sum_{l=1}^{n}(-1)^{(l+j)}\left(\varphi_{l, k} \Delta_{l, j}(k, T) / \Delta(k, T)+(-1)^{(n)} \varphi_{n+l, k} \Delta_{n+l, j}(k, T) / \Delta(k, T)\right), \\
C_{k, n+j}=\sum_{l=1}^{n}(-1)^{(l+j)}\left((-1)^{(n)} \varphi_{l, k} \Delta_{l, n+j}(k, T) / \Delta(k, T)+\varphi_{n+l, k} \Delta_{n+l, n+j}(k, T) / \Delta(k, T)\right),
\end{array}\right.
$$

where $\Delta_{l, j}(k, T), l, j \in\{1, \ldots, 2 n\}$, is complementary minor of the element being intersecion of the $l$ th raw and $j$ th column in the determinant $\Delta(k, T)$.

All cofactors $\Delta_{l, j}(k, T), l, j \in\{1, \ldots, 2 n\}$ are calculated by analogy with $\Delta(k)$. In particular, 
for $r, q \in\{1, \ldots, n\}$, one can obtain

$$
\begin{aligned}
& \Delta_{r, q}(k)=\left|\begin{array}{cccccc}
1 & \ldots & 1 & 1 & \ldots & 1 \\
\eta_{1}^{2} & \ldots & \eta_{q-1}^{2} & \eta_{q+1}^{2} & \ldots & \eta_{n}^{2} \\
\ldots \ldots \ldots \ldots \ldots \ldots \ldots \ldots \ldots \ldots \ldots \ldots \ldots \ldots \ldots \\
\eta_{1}^{2(r-2)} & \ldots & \eta_{q-1}^{2(r-2)} & \eta_{q+1}^{2(r-2)} & \ldots & \eta_{n}^{2(r-2)} \\
\eta_{1}^{2 r} & \ldots & \eta_{q-1}^{2 r} & \eta_{q+1}^{2 r} & \ldots & \eta_{n}^{2 r} \\
\ldots \ldots \ldots \ldots \ldots \ldots \ldots \ldots \ldots \ldots \ldots \ldots \ldots \ldots & \ldots \ldots \ldots \ldots \\
\eta_{1}^{2(n-1)} & \ldots & \eta_{q-1}^{2(n-1)} & \eta_{q+1}^{2(n-1)} & \ldots & \eta_{n}^{2(n-1)}
\end{array}\right|
\end{aligned}
$$

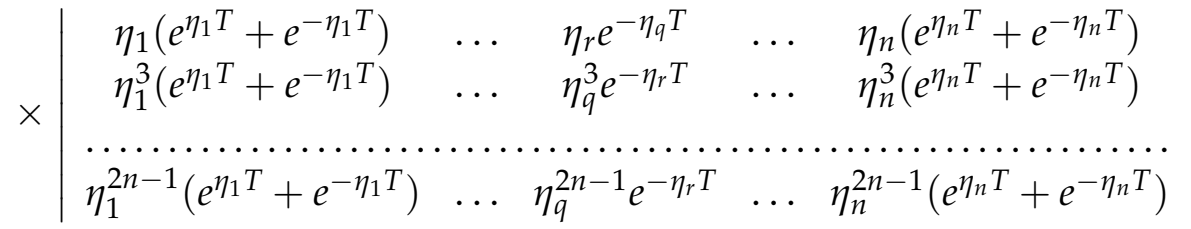

$$
\begin{aligned}
& =(-1)^{n-q} e^{-\eta_{q} T} \eta_{q} S_{n-2 r+1}^{(q)} \prod_{\substack{1 \leq s<l \leq n \\
s, l \neq q}}\left(\eta_{s}^{2}-\eta_{l}^{2}\right)^{2} \prod_{\substack{j=1 \\
j \neq q}}^{n}\left(\eta_{j}\left(e^{\eta_{j} T}+e^{-\eta_{j} T}\right)\right) \prod_{\substack{s=1 \\
s \neq q}}^{n}\left(\eta_{q}^{2}-\eta_{s}^{2}\right),
\end{aligned}
$$

where $S_{\ell}^{(q)}, \ell \in\{1, \ldots, n-1\}$ is the sum of all possible products of the elements $\eta_{1}^{2}, \ldots, \eta_{q-1}^{2}$ $\eta_{q+1}^{2}, \ldots, \eta_{n}^{2}$, taking $\ell$ elements in every product; $S_{0}^{(q)} \equiv 1$.

The next results one can get by analogy

$$
\begin{gathered}
\Delta_{n+r, q}(k)=(-1)^{2 n-q-1} S_{n-2 r+1}^{(q)} \prod_{\substack{1 \leq s<l \leq n \\
s, l \neq q}}\left(\eta_{s}^{2}-\eta_{l}^{2}\right)^{2} \prod_{\substack{j=1 \\
j \neq q}}^{n}\left(\eta_{j}\left(e^{\eta_{j} T}+e^{-\eta_{j} T}\right)\right) \prod_{\substack{s=1 \\
s \neq q}}^{n}\left(\eta_{q}^{2}-\eta_{s}^{2}\right), \\
\Delta_{r, n+q}(k)=(-1)^{2 n-q-1} e^{\eta_{q} T} \eta_{q} S_{n-2 r+1}^{(q)} \prod_{\substack{1 \leq s<l \leq n \\
s, l \neq q}}\left(\eta_{s}^{2}-\eta_{l}^{2}\right)^{2} \prod_{\substack{j=1 \\
j \neq q}}^{n}\left(\eta_{j}\left(e^{\eta_{j} T}+e^{-\eta_{j} T}\right)\right) \prod_{\substack{s=1 \\
s \neq q}}^{n}\left(\eta_{q}^{2}-\eta_{s}^{2}\right), \\
\Delta_{n+r, n+q}(k)=(-1)^{n-q} S_{n-2 r+1}^{(q)} \prod_{\substack{1 \leq s<l \leq n \\
s, l \neq q}}\left(\eta_{s}^{2}-\eta_{l}^{2}\right)^{2} \prod_{\substack{j=1 \\
j \neq q}}^{n}\left(\eta_{j}\left(e^{\eta_{j} T}+e^{-\eta_{j} T}\right)\right) \prod_{\substack{s=1 \\
s \neq q}}^{n}\left(\eta_{q}^{2}-\eta_{s}^{2}\right) .
\end{gathered}
$$

So there is unique solution $u_{k}(t)$ of the problem (3), (4) for every $k \in \mathbb{Z}$. Formal solution of the problem (1), (2) after realizing all necessary calculations can be represented as a series in the form

$$
u(t, x)=u_{0}(t)+\sum_{|k|>0} e^{i k x} \sum_{q, j=1}^{n} S_{n-j}^{(q)} \frac{\varphi_{j k} \lambda_{q} k e^{i k h} \operatorname{ch}\left(\lambda_{q} k e^{i k h}(T-t)\right)+\varphi_{n+j, k} \operatorname{sh}\left(\lambda_{q} k e^{i k h} t\right)}{(-1)^{n+j} \lambda_{q}\left(k e^{i k h}\right)^{2 n-1} \operatorname{ch}\left(k \lambda_{q} e^{i k h} T\right) \prod_{s=1, s \neq q}^{n}\left(\lambda_{s}^{2}-\lambda_{q}^{2}\right)^{\prime}}
$$

where $k \in \mathbb{Z} \backslash\{0\}, u_{0}(t)$ is defined by the formula (8).

Convergence of the series (15) is associated with the small denominators problem, since nonzero $\left|\operatorname{ch}\left(\lambda_{j} k T e^{i k h}\right)\right|, j=1, \ldots, n$, can take the arbitrarily small values for the infinite quantity of integer numbers $k$.

Theorem 2. Let the condition (11) be satisfied and there exists the constant $\omega$, such that for all numbers $k \in \mathbb{Z}$ the next inequalities

$$
\left|\operatorname{ch}\left(\lambda_{j} k T e^{i k h}\right)\right| \geq(1+|k|)^{-\omega} e^{T\left|\operatorname{Re}\left(\lambda_{j} k e^{i k h}\right)\right|}, \quad j=1, \ldots, n,
$$

are true. If $\varphi_{j} \in H_{\alpha+\omega+2 n}, \varphi_{n+j} \in H_{\alpha+\omega+2 n-1}, j=1, \ldots, n$, then the unique solution of the problem (1), (2) exists in the space $C^{2 n}\left([0, T] ; H_{\alpha}\right)$ and continuously depends on $\varphi_{j}$, $j=1, \ldots, 2 n$. 
Proof. Assuming that $\varphi_{j} \in H_{\alpha+\omega+2 n-1}, j=0,1, \ldots, 2 n$, the aim is to demonstrate that the series (15) belongs to the space $C^{2 n}\left([0, T] ; H_{\alpha}\right)$ and is the solution of the problem (1), (2). Let us majorize the value $\max _{t \in[0, T]}\left|u_{k}^{(q)}(t)\right|$ for all $k \in \mathbb{Z}$ and $q=0,1, \ldots, 2 n$. Due to the formulas (8), (15) and estimations (16) one can get:

$$
\begin{gathered}
\max _{t \in[0, T]}\left|u_{0}^{(q)}(t)\right| \leq 2 n\left|\varphi_{j 0}\right| \max _{\substack{t \in[0, T] \\
\ell, j=1, \ldots, 2 n}}\left|\frac{(j-1) !}{(j-q-1) !} \frac{\Delta_{j \ell}(0)}{\Delta(0)} t^{j-q-1}\right|, \quad q=0, \ldots, 2 n, \\
\max _{t \in[0, T]}\left|u_{k}^{(q)}(t)\right| \leq C_{1} \sum_{j=1}^{n}\left(\left|\varphi_{j k}\right|(1+|k|)^{\omega+q}+\left|\varphi_{n+j, k}\right|(1+|k|)^{\omega+q-1}\right), \quad q=0, \ldots, 2 n .
\end{gathered}
$$

The next formula follows from the inequalities (17) and (18)

$$
\begin{aligned}
\| u(t, x) & ; C^{2 n}\left([0, T] ; H_{\alpha}\right) \| \leq C_{2} \sum_{q=0}^{2 n}\left(\sum_{|k| \geq 0} \max _{t \in[0, T]}\left|u_{k}^{(q)}(t)\right|^{2}(1+|k|)^{2 \alpha}\right)^{1 / 2} \\
\leq & C_{3} \sum_{j=1}^{n}\left(\sum_{|k| \geq 0}\left|\varphi_{j k}\right|^{2} w_{k}(\alpha+\omega+2 n)\right)^{1 / 2}+C_{4} \sum_{j=n+1}^{2 n}\left(\sum_{|k| \geq 0}\left|\varphi_{j k}\right|^{2} w_{k}(\alpha+\omega+2 n-1)\right)^{1 / 2} \\
& =C_{5}\left(\sum_{j=1}^{n}\left\|\varphi_{j}(x) ; H_{\alpha+\omega+2 n}\right\|+\sum_{j=n+1}^{2 n}\left\|\varphi_{j}(x) ; H_{\alpha+\omega+2 n-1}\right\|\right)<\infty
\end{aligned}
$$

The statement of this theorem can be obtained from the above inequality.

Theorem 3. For almost all (with respect to Lebesgue measure in $\mathbb{R}$ ) numbers $h \in(0,2 \pi)$ all inequalities (16) are true for all (except for the finite quantity) numbers $k \in \mathbb{Z}$, if $\omega>1$.

Proof. To prove the theorem it is sufficient to verify that, if $\omega>1$ for almost all values $h \in \Omega$ every inequality $\left|\cos \left(T \operatorname{Im}\left(\lambda_{j} k e^{i k h}\right)\right)\right| \geq(1+|k|)^{-\omega}, j=1, \ldots, n$, is true for all (except for the finite quantity) integer numbers $k$. Due to the Borel-Cantelli lemma it is sufficient to establish that the series $\sum_{k \in \mathbb{Z}}$ mes $M_{j, \omega}(k), j=1, \ldots, n$, is convergent, if $\omega>1$, where $M_{j, \omega}(k) \equiv\{h \in$ $\left.\Omega:\left|\cos \left(T \operatorname{Im}\left(\lambda_{j} k e^{i k h}\right)\right)\right| \leq(1+|k|)^{-\omega}\right\}, j=1, \ldots, n$. Let $\lambda_{j}=\left|\lambda_{j}\right| e^{i \eta_{j}}, j=1, \ldots, n$, where $\eta_{j}$ is an argument of the complex number $\lambda_{j}$. Then $\operatorname{Im}\left(\lambda_{j} e^{i k h}\right)=\left|\lambda_{j}\right| \sin \left(k h+\eta_{j}\right), j=1, \ldots, n$. Let us consider the case $k>0$. It is obviously

$$
\begin{aligned}
\operatorname{mes} M_{j, \omega}(k) & =k^{-1} \operatorname{mes}\left\{H \in(0,2 \pi k):\left|\cos \left(T\left|\lambda_{j} k\right| \sin \left(H+\eta_{j}\right)\right)\right| \leq(1+|k|)^{-\omega}\right\} \\
& =k^{-1} \operatorname{mes}\left\{H \in\left(\eta_{j}, \eta_{j}+2 \pi k\right): \mid \cos \left(T\left|\lambda_{j} k \sin H\right|\right) \leq(1+|k|)^{-\omega}\right\} .
\end{aligned}
$$

Let us partition the interval $\left[\eta_{j}, \eta_{j}+2 \pi k\right]$ for the assigned $\delta \in(1, \omega-3)$ by the uncountinuable intervals and intervals $I_{q}, q=\overline{1, N_{1}(k)}$, and intervals $J_{q}, q=\overline{1, N_{2}(k)}$, to accomplish the next conditions $\forall H \in I_{q}|\cos H| \geq 1 / k^{\delta+1}, q=\overline{1, N_{1}(k)}$, and $\forall H \in J_{q}|\cos H| \leq 1 / k^{\delta+1}$, $q=\overline{1, N_{2}(k)}$. For the numbers $N_{1}(k), N_{2}(k)$ the following inequalities are true $N_{1}(k) \leq C_{4} k$, $N_{2}(k) \leq C_{5} k$. Since mes $J_{q} \leq C_{6} k^{-\delta-1}, q=\overline{1, N_{2}(k)}$, then mes $\left(\bigcup_{q=1}^{N_{2}(k)} J_{q}\right) \leq C_{7} k^{-\delta}$. Because of

$$
\begin{aligned}
\operatorname{mes}\left\{H \in I_{q}:\right. & \left.\left|\cos \left(T\left|\lambda_{j} k\right| \sin H\right)\right| \leq(1+|k|)^{-\omega}\right\} \\
& \leq k^{1+\delta} \operatorname{mes}\left\{t \in \sin \left(I_{q}\right):\left|\cos \left(T\left|\lambda_{j} k\right| t\right)\right| \leq(1+|k|)^{-\omega}\right\} \\
& \leq k^{1+\delta} \text { mes }\left\{t \in[-1 ; 1]:\left|\cos \left(T\left|\lambda_{j} k\right| t\right)\right| \leq(1+|k|)^{-\omega}\right\} .
\end{aligned}
$$


By [11, Lemma 2.2] mes $\left\{t \in[-1 ; 1]:\left|\cos \left(T\left|\lambda_{j} k\right| t\right)\right| \leq(1+|k|)^{-\omega}\right\} \leq C_{8}(1+|k|)^{1-\omega}$. In this way for $k>0$

$$
\begin{aligned}
\operatorname{mes} M_{j, \omega}(k) & \leq C_{9} \sum_{q=1}^{N_{2}(k)} \operatorname{mes}\left\{H \in I_{q}:\left|\cos \left(T\left|\lambda_{j} k\right| \sin H\right)\right| \leq(1+|k|)^{-\omega}\right\} \\
& +C_{10} \sum_{q=1}^{N_{2}(k)} \operatorname{mes} J_{q} \leq C_{11} k^{-\delta}+C_{12} k^{2+\delta-\omega}
\end{aligned}
$$

The case $k<0$ is considered analogically. The series $\sum_{k \in \mathbb{Z}}$ mes $M_{j, \omega}(k), j=1, \ldots, n$, convergence is stated.

Theorem 4. The inequalities (16) are true for almost all (with respect to Lebesgue measure in $\mathbb{R}$ ) numbers $T$ and for all (except the finite quantity) numbers $k \in \mathbb{Z}$, if $\omega>0$.

Proof. Satisfaction of the inequalities (16) for every $k \in \mathbb{Z}$ is identical to satisfaction of the next estimations

$$
\left|1+e^{-2 \lambda_{j} k T e^{i k h}}\right| \geq(1+|k|)^{-\omega}, \quad j=1, \ldots, n .
$$

Choosing $j$ th inequality from (19), one can note $l(T, k):=\left(1+e^{-2 \lambda_{j} k T e^{i k h}}\right)$. It is easy to show, that for every $T \in(0,+\infty)$ and for every $k \in \mathbb{Z}^{p}$ the following equality

$$
l(T, k)+\frac{\partial l(T, k)}{\partial T}\left(2 \lambda_{j} k e^{i k h}\right)^{-1}=1
$$

is true. Whence

$$
\max \left\{|l(T, k)|,\left|\frac{\partial l(T, k)}{\partial T}\left(2 \lambda_{j} k e^{i k h}\right)^{-1}\right|\right\} \geq 1 / 2, \quad T \in(0,+\infty), \quad k \in \mathbb{Z}^{p} .
$$

Let us consider the function

$$
z(T, k):=|l(T, k)|-\left|\frac{\partial l(T, k)}{\partial T}\left(2 \lambda_{j} k e^{i k h}\right)^{-1}\right|, \quad T \in(0,+\infty), \quad k \in \mathbb{Z}^{p},
$$

as function of the variable $T$ and parameter $k$ and find the number of zeroes of this function on the interval $(0,+\infty)$. Basing on (20) and (22) one can get that zeroes of this function coincide with the zeroes of the function

$$
z_{1}(T, k):=l(T, k)-\frac{\partial l(T, k)}{\partial T}\left(2 \lambda_{j} k e^{i k h}\right)^{-1}=2 e^{-2 \lambda_{j} k T e^{i k h}}+1 .
$$

Equation $2 e^{-2 \lambda_{j} k T e^{i k h}}+1=0$ is equivalent to the next system

$$
\left\{\begin{array}{l}
2 \cos \left(2 k T\left(\operatorname{Re} \lambda_{j} \sin k h+\operatorname{Im} \lambda_{j} \cos k h\right)\right)=-e^{2 k T\left(\operatorname{Re} \lambda_{j} \cos k h-\operatorname{Im} \lambda_{j} \sin k h\right),} \\
\sin \left(2 k T\left(\operatorname{Re} \lambda_{j} \sin k h+\operatorname{Im} \lambda_{j} \cos k h\right)\right)=0,
\end{array} \quad k \in \mathbb{Z}^{p} .\right.
$$

The existence of a solution in relation to $T$ for the system (23) is obvious. Moreover it is unique, only for those values of the vector parameter $k \in \mathbb{Z}$, for which $\operatorname{Re} \lambda_{j} \cos k h-$ $\operatorname{Im} \lambda_{j} \sin k h \neq 0$, and $\left.\ln 4\left(\operatorname{Re} \lambda_{j} \sin k h+\operatorname{Im} \lambda_{j} \cos k h\right)\right) /\left(\pi\left(\operatorname{Re} \lambda_{j} \cos k h-\operatorname{Im} \lambda_{j} \sin k h\right)\right)$ is odd integer number. The set of these integers $k \in \mathbb{Z}$ would be denoted as $K$. Solution of the system (23) is positive and can be represented as follows

$$
\tilde{T}(k)=\frac{\ln 4}{4 k\left(\operatorname{Re} \lambda_{j} \cos k h-\operatorname{Im} \lambda_{j} \sin k h\right)}, \quad k \in K .
$$


Let us consider the interval $\left(0, T_{0}\right]$, where $0<T_{0}<+\infty$, and introduce the following notation: $E\left(T_{0}\right)$ would be the set of those values $T \in\left(0, T_{0}\right]$, in case the next inequality

$$
|l(T, k)|<C_{4}(1+|k|)^{-\omega}
$$

is true for the infinite integers quantity $k \in \mathbb{Z} ; E\left(T_{0}, \bar{k}\right)$ is the set of those values $T \in\left(0, T_{0}\right]$, in case the next inequality (24) is true at fixed $k=\bar{k} \in \mathbb{Z} ; E_{1}\left(T_{0}, \bar{k}\right)$ and $E_{2}\left(T_{0}, \bar{k}\right)$ are the sets of those values $T \in\left(0, T_{0}\right]$, in case the inequalities $|\operatorname{Re} l(T, k)|<C_{4}(1+|k|)^{-\omega}$ and $|\operatorname{Im} l(T, k)|<$ $C_{4}(1+|k|)^{-\omega}$, respectively, are true at fixed $k=\bar{k} \in \mathbb{Z} ; K_{1}=\left\{k \in K: \tilde{T}(k) \geq T_{0}\right\} ; K_{2}=$ $(\mathbb{Z} \backslash K) \cup K_{1}$.

There are no zeroes of the function $z$ on the interval $\left(0, T_{0}\right]$, if $\bar{k} \in K_{2}$. Denoting $K_{3}=\{k \in$ $\left.K_{2}: z(T, k)>0, T \in\left(0, T_{0}\right]\right\}$ and using (21), (22), one can obtain at $\bar{k} \in K_{3}:|l(T, \bar{k})| \geq 1 / 2$, $T \in\left(0, T_{0}\right]$. Hence,

at $C_{4}<1 / 2$.

$$
\operatorname{mes}_{\mathbb{R}}\left(E\left(T_{0}, \bar{k}\right)\right)=0, \quad \bar{k} \in K_{3},
$$

If $\bar{k} \in K_{2} \backslash K_{3}$, then $z(T, \bar{k})<0$ for all $T \in\left(0, T_{0}\right]$; due to the (21), (22) one can get

$$
\left|\frac{\partial l(T, \bar{k})}{\partial T}\right| \geq 2 \lambda_{j}|\bar{k}|, \quad T \in\left(0, T_{0}\right], \quad \bar{k} \in K_{2} \backslash K_{3} .
$$

The estimations (26) ensue that for all (except the finite quantity) integers $\bar{k}$ one of the inequalities

is true, where $T \in\left(0, T_{0}\right], \bar{k} \in K_{2} \backslash K_{3}$.

$$
\left|\frac{\partial}{\partial T}(\operatorname{Re} l(T, \bar{k}))\right| \geq \lambda_{j}|\bar{k}|, \quad\left|\frac{\partial}{\partial T}(\operatorname{Im} l(T, \bar{k}))\right| \geq \lambda_{j}|\bar{k}|,
$$

According to [11, Lemma 2.2] and to estimations (27) it follows that for all (except the finite quantity) integers $\bar{k}$ one of the inequalities

$$
\operatorname{mes}_{\mathbb{R}} E_{1}\left(T_{0}, \bar{k}\right) \leq C_{5}(1+|\bar{k}|)^{-(\omega+1)}, \quad \operatorname{mes}_{\mathbb{R}} E_{2}\left(T_{0}, \bar{k}\right) \leq C_{5}(1+|\bar{k}|)^{-(\omega+1)},
$$

is true, where $\bar{k} \in K_{2} \backslash K_{3}$; since $E\left(T_{0}, \bar{k}\right) \subset E_{1}\left(T_{0}, \bar{k}\right), E\left(T_{0}, \bar{k}\right) \subset E_{2}\left(T_{0}, \bar{k}\right)$, and taking into account the inequalities (28), one can get

$$
\operatorname{mes}_{\mathbb{R}} E\left(T_{0}, \bar{k}\right) \leq C_{5}(1+|\bar{k}|)^{-(\omega+1)}, \quad \bar{k} \in K_{2} \backslash K_{3} .
$$

As a consequence of formulae (25) and (29) the next estimation

$$
\operatorname{mes}_{\mathbb{R}} E\left(T_{0}, \bar{k}\right) \leq C_{5}(1+|\bar{k}|)^{-(\omega+1)}, \quad \bar{k} \in K_{2},
$$

is true for all (except the finite quantity) integers $\bar{k}$.

The function $z$ has one zero $\tilde{T}(\bar{k})$, belonging to the interval $\left(0, T_{0}\right]$, if $\bar{k} \in K \backslash K_{1}$. Under this condition one can realize partition of the interval $\left(0, T_{0}\right]$ into the intervals $J_{1}=(0, \tilde{T})$ and $J_{2}=\left(\tilde{T}, T_{0}\right]$. There are no zeroes of the function $z$ on every of these intervals. Realizing analogical illustrations similar to the above, on the intervals $J_{1}$ and $J_{2}$ one can obtain that on the interval $\left(0, T_{0}\right]$ the following estimation

$$
\operatorname{mes}_{\mathbb{R}} E\left(T_{0}, \bar{k}\right) \leq 2 C_{5}(1+|\bar{k}|)^{-(\omega+1)}, \quad \bar{k} \in K \backslash K_{1},
$$

is true for all (except the finite quantity) integers $\bar{k}$ on the interval $\left(0, T_{0}\right]$.

Adding up the estimations (30) and (31) by $k \in K_{2}$ and $k \in K \backslash K_{1}$, respectively, in reference to measure of the set $E\left(T_{0}\right)$ can be obtained the next estimation

$$
\operatorname{mes}_{\mathbb{R}} E\left(T_{0}\right) \leq C_{6} \sum_{k \in \mathbb{Z}^{p}}(1+|k|)^{-(\omega+1)} .
$$


The series in the right-hand side of the inequality (32) is convergent, if $\omega>0$. Via BorelCantelli lemma mes $\mathbb{R}_{\mathbb{R}} E\left(T_{0}\right)=0$. Namelly, the inverse inequality to the inequality (24) is true for almost all $T \in\left(0, T_{0}\right]$ for all (except the finite quantity) of integers $k \in \mathbb{Z}$. The fact that interval $(0,+\infty)$ can be covered by the countable quantity of the intervals with the length $T_{0}$, proves the theorem.

As a result of the Theorems 2, 3 and 4 the next statements can be formulated.

Corollary 1. Let the condition (11) be satisfied. If $\varphi_{j} \in H_{\alpha+\omega+2 n}, \varphi_{n+j} \in H_{\alpha+\omega+2 n-1}, j=$ $1, \ldots, n, \omega>1$, then for almost all (with respect to Lebesgue measure in $\mathbb{R}$ ) numbers $h \in$ $(0,2 \pi)$ the unique solution of the problem (1), (2) exists in the space $C^{2 n}\left([0, T] ; H_{\alpha}\right)$ and continuously depends on $\varphi_{j}, j=1, \ldots, 2 n$.

Corollary 2. Let the condition (11) be satisfied. If $\varphi_{j} \in H_{\alpha+\omega+2 n}, \varphi_{n+j} \in H_{\alpha+\omega+2 n-1}, j=$ $1, \ldots, n, \omega>0$, then for almost all (with respect to Lebesgue measure in $\mathbb{R}$ ) numbers $T>0$ the unique solution of the problem (1), (2) exists in the space $C^{2 n}\left([0, T] ; H_{\alpha}\right)$ and continuously depends on $\varphi_{j}, j=1, \ldots, 2 n$.

Remark 2. Results of this paper can be carried on the case of Dirichlet-Neumann problem for the partial differential equations systems.

\section{Conclusions}

The correctness of Dirichlet-Neumann problem for the partial differential equations with deviating space argument is studied. There are established conditions of the unique solution existence for this problem in Sobolev spaces scale. The metric theorems on the estimations of the small denominators appearing in the solution's construction are proved.

\section{References}

[1] Andreev A.A. Analogs of classical boundary value problems for a second-order differential equation with deviating argument. Differ. Equ. 2004, 40 (8), 1192-1194. doi:10.1023/B:DIEQ.0000049836.04104.6f (translation of Differ. Uravn. 2004, 40 (8), 1126-1128. (in Russian))

[2] Antonevich A.B. Linear differential equations. Operator approach. University, Minsk, 1988. (in Russian)

[3] Assanova A.T., Iskakova N.B., Orumbayeva N.T. Well-posedness of a periodic boundary value problem for the system of hyperbolic equations with delayed argument. Bull. Karaganda Univ. Ser. Math. 2018,89 (1), 8-14. doi:10.31489/2018M1/8-14

[4] Baranetskij Ya.O., Kalenyuk P.I., Kolyasa L.I., Kopach M.I. The nonlocal problem for the differentialoperator equation of the even order with the involution. Carpathian Math. Publ. 2017, 9 (2), $109-119$. doi:10.15330/cmp.9.2.109-119

[5] Baranetskij Ya.O., Demkiv I.I., Ivasiuk I.Ya., Kopach M.I. The nonlocal problem for the $2 n$ differential equations with unbounded operator coefficients and the involution. Carpathian Math. Publ. 2018, 10 (1), 14-30. doi:10.15330/cmp.10.1.14-30

[6] Bzheumikhova O.I., Lesev V.N. On the solvability of nonlinear partial differential equations of a high order with deviating argument in lowest terms. Russian Math. 2016, 60 (7), 7-13. doi:10.3103/S1066369X16070021 (translation of Iz. VUZ. Mat. 2016, 7, 10-17. (in Russian))

[7] Bobyk I.O., Symotiuk M.M. Dirichlet-type problem for the equations with partial derivatives with delay argument. Sci. Bull. Uzhhorod Univ. Ser. Math. Inf. 2017, 31 (2), 21-27. (in Ukrainian) 
[8] Iskakova N.B., Ikrambekova D.K. On algorithms for finding a solution to the periodic boundary value problem for linear differential equations with delay argument. Bull. Abai KazNPU Ser. Phys. Math. Sci. 2013, 4 (44), 95-99. (in Russian)

[9] Malanchuk O., Nytrebych Z. Homogeneous two-point problem for PDE of the second order in time variable and infinite order in spatial variables. Open Math. 2017, 15 (1), 101-110. doi:10.1515/math-2017-0009

[10] Myshkis A.D. Stability of linear mixed functional-differential equations with commensurable deviations of the space argument. Differ. Equ. 2002, 38 (10), 1415-1422. doi:10.1023/A:1022366528667 (translation of Differ. Uravn. 2002, 38 (10), 1331-1337. (in Russian))

[11] Ptashnyk B.Yo. Ill-posed boundary problems for partial differential equations. Naukova Dumka, Kyiv, 1984. (in Russian)

[12] Ptashnyk B.Yo., Il'kiv V.S., Kmit' I.Ya., Polishchuk V.M. Nonlocal boundary value problems for partial differential equations. Naukova Dumka, Kyiv, 2002. (in Ukrainian)

[13] Ptashnyk, B.Y., Repetylo, S.M. Dirichlet-Neumann problem for systems of hyperbolic equations with constant coefficients. J. Math. Sci. 2016, 215 (1), 26-35. doi:10.1007/s10958-016-2819-9 (translation of Mat. Met. Fiz.-Mekh. Polya 2014, 57 (2), 25-31. (in Ukrainian))

[14] Ptashnyk, B.Y., Repetylo, S.M. Dirichlet-Neumann problem in a strip for hyperbolic equations with constant coefficients. J. Math. Sci. 2015, 205 (4), 501-517. doi:10.1007/s10958-015-2263-2 (translation of Mat. Met. Fiz.-Mekh. Polya 2013, 56 (3), 15-28. (in Ukrainian))

[15] Hale J. Theory of functional differential equations. Nauka, Moscow, 1984. (in Russian)

Received 10.05.2020

Revised 29.03.2021

Пукач П.Я., Репетило С.М., Симотюк М.М., Вовк М.І. Задача типу Аіріхле-Неймана для рівнянь із иастинними похідними з відхиленим просторовим аргументом // Карпатські матем. публ. 2021. — T.13, №2. - С. 315-325.

В області, шо є декартовим добутком відрізка $(0, T)$ і одиничного кола $\Omega=\mathbb{R} /(2 \pi \mathbb{Z})$, розглянуто задачу Аіріхле-Неймана для безтипного диференціального рівняння з частинними похідними високого порядку з відхиленням просторового аргументу. Задачі Аіріхле-Неймана для гіперболічних рівнянь та їх систем, якшо відхилення $h$ аргументів відсутні, вивчалися авторами раніше. Аля таких задач було встановлено умови однозначної розв'язаності для майже всіх (стосовно міри побулованих з коефіцієнтів рівняння.

У цій роботі встановлено умови розв'язності задачі у випадку $h \neq 0$ та досліджено вплив відхилення $h$ на розв'язність задачі. Розв'язок задачі побуловано у вигляді рялу за системою ортогональних функцій. Аля малих знаменників, які виникли при побудові розв' язку задачі, доведено метричні оцінки (експоненційного типу), які гарантують коректність задачі у просторах Соболева для майже всіх (стосовно міри $\Lambda$ ебега) значень $T>0$ і для майже всіх (стосовно міри Аебега) значень $h \in[0,2 \pi)$. Ці результати отримано завдяки тому, шо відповідний характеристичний визначник допускає факторизацію у формі добутку гіперболічних функцій з цілими параметрами.

Ключові слова і фрази: задача Аіріхле-Неймана, рівняння із частинними похідними, відхилення просторового аргументу, малі знаменники, метричний підхід. 